\title{
Two-dimensional Cutting Simulation of SiCp/Al Composites
}

\author{
Kai Yang ${ }^{1,2}$, Yingwei Zhang ${ }^{2}$, Jia Li ${ }^{2}$, Qingfei Jiang ${ }^{1, ~}{ }^{*}$, Xiaodong Xia ${ }^{1}$ \\ ${ }^{1}$ Post-doctoral Scientific Research Station in Nanjing General Hospital of Former Nanjing Military \\ Region,Nanjing,Jiangsu 210000, China \\ ${ }^{2}$ Army Aviation Institute, Beijing 101123, China \\ *email: jafgzz@163.com
}

Keywords: SiCp/Al, metal matrix composite, fracture pattern, FE simulation

Absract: Finite element analysis software Abaqus was used to establish a two-dimensional microscopic finite element model of $\mathrm{SiCp} / \mathrm{Al}$ composites. The $\mathrm{SiC}$ particles and the aluminum matrix were defined respectively, and the cutting process was simulated and simulated. The fracture pattern of $\mathrm{SiC}$ particles was also studied. For the follow-up to improve the processing of dimensional accuracy, reduce the surface roughness of the workpiece to provide relevant data support.

\section{Introduction}

As a kind of metal matrix composite material, $\mathrm{SiCp} / \mathrm{Al}$ composite material has a series of excellent properties and is widely used in the aerospace field, automobile industry, and electronic and optical instruments. However, due to the poor mechanical processing performance of SiCp/Al composites, it has hindered the development and application of this kind of material. At present, for the research of $\mathrm{SiCp} / \mathrm{Al}$ composite materials, foreign researchers have made great achievements in experimental research and finite element simulation analysis, while studies by domestic scholars are mainly focused on experimental research, relatively few studies on finite element analysis of the cutting mechanism of $\mathrm{SiCp} / \mathrm{Al}$ composites[1]. In this paper, based on the finite element analysis software Abaqus, a cutting simulation model of $\mathrm{SiCp} / \mathrm{Al}$ composites is established from a microscopic point of view, and the material removal mechanism and chip formation mechanism during the cutting process are analyzed to study the influence of different cutting parameters on the cutting force. The parameters are optimized to provide basis for solving the problems of precision and ultra-precision cutting of the material.

\section{Two-dimensional finite element model of $\mathrm{SiCp} / \mathrm{Al}$ composites}

In order to describe the microstructure of $\mathrm{SiCp} / \mathrm{Al}$ composites more accurately, the $\mathrm{Al}$ matrix and the $\mathrm{SiC}$ particles were separated by the segmentation method, and the material properties were defined respectively. The research object is $\mathrm{SiCp} / \mathrm{Al}$ composite material with $\mathrm{SiC}$ particle diameter of $40 \mu \mathrm{m}$ and volume fraction of $30 \%$. The tool adopts PCD tool, tool length is $3 \mathrm{~mm}$, height is $3.5 \mathrm{~mm}$, rake angle is $5^{\circ}$ and edge radius is $1.5 \mu \mathrm{m}$. Finally, the two-dimensional orthogonal cutting model was established.

\section{Establishment of finite element simulation model}

The finite element models of SiC particles and 2024Al matrix were established separately, and the entire cutting process was simplified into a two-dimensional plane strain problem [2]. In the modeling process, the aluminum matrix is regarded as a thermoelastic-plastic model, the SiC particles are considered as a linear elastic model, and the tool is set as a rigid body. 


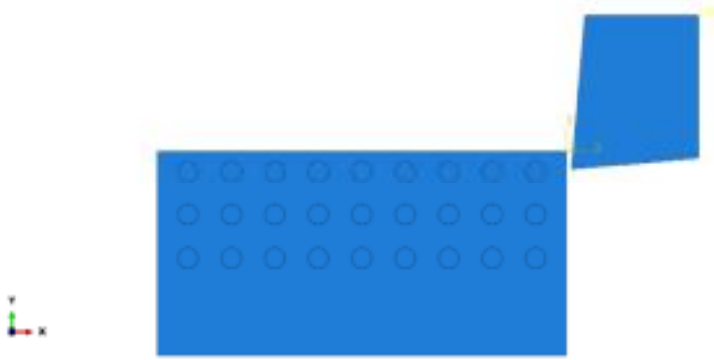

Fig.1 the microcosmic geometric model of $\mathrm{SiCp} / \mathrm{Al}$ composite cutting

Material parameter setting and constitutive model of $\mathrm{SiC}_{\mathrm{p}} / \mathrm{Al}$ composites

The material parameters used in this paper are shown in Table 1.

Table 1 Basic Physical and Mechanical Parameters of SiC and PCD[3-6]

\begin{tabular}{cccc}
\hline Material properties & $\mathrm{SiC}$ & PCD & $2024 \mathrm{Al}$ \\
\hline Density $\left(\mathrm{kg} / \mathrm{m}^{3}\right)$ & $3.22 \times 10^{3}$ & $3.55 \times 10^{3}$ & $2.82 \times 10^{3}$ \\
\hline $\begin{array}{c}\text { Elastic modulus } \\
(\mathrm{GPa})\end{array}$ & 410 & 850 & 70 \\
\hline Poisson's ratio & 0.14 & 0.08 & 0.3 \\
\hline Yield stress $(\mathrm{MPa})$ & $4.9 \times 10^{-6}$ & & 355 \\
\hline Specific Heat & & & 670 \\
capacity $\left(\mathrm{J} \cdot \mathrm{kg}^{-1} \cdot{ }^{\circ} \mathrm{C}^{-1}\right)$ & 670 & & \\
\hline
\end{tabular}

\section{Analysis of cutting simulation results}

In this paper, in the case of $40 \mu \mathrm{m} \mathrm{SiC}$ round particles and cutting speed of $500 \mathrm{~mm} / \mathrm{s}$, the fracture morphology of the simulated tool at different positions was simulated. When the cutting path of the tool is located above the grain, there are mainly two types of fracture of the SiC grains, as shown in Figs. 2 and 3 .

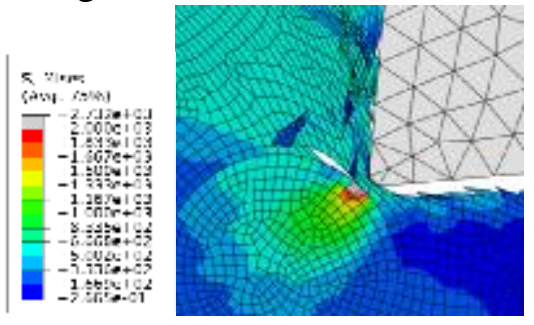

(a)

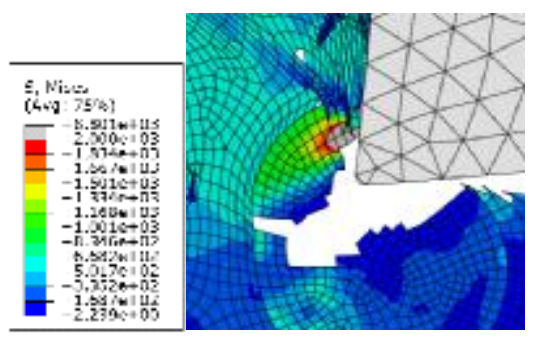

(c)

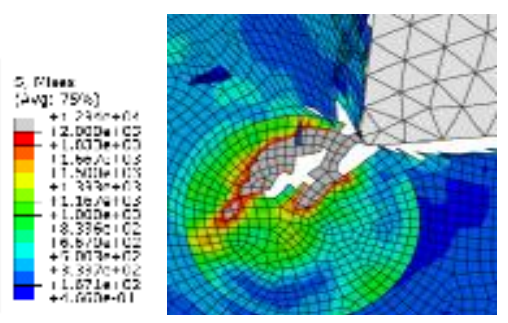

(b)

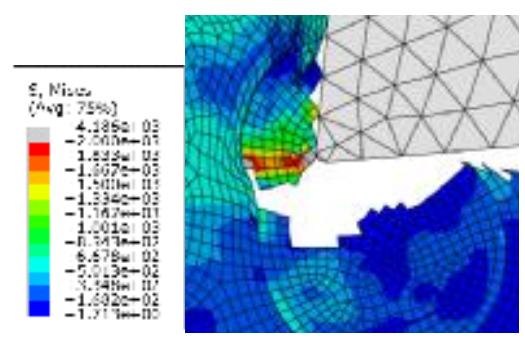

(d)

Fig.2 SiC Particle Breaking Form I: (a) $\rightarrow$ (b) $\rightarrow(\mathrm{c}) \rightarrow(d)$ 


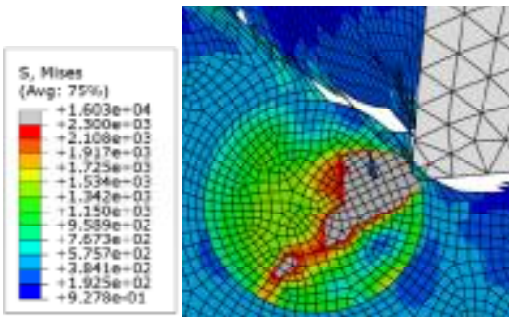

(a)

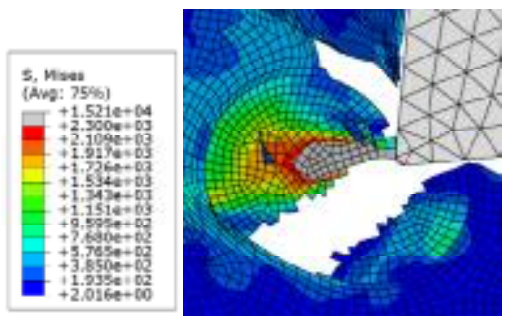

(c)

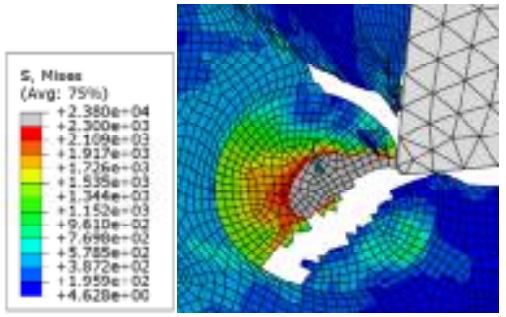

(b)

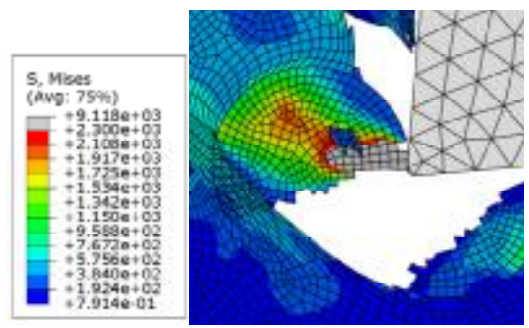

(d)

Fig.3 SiC Particle Breaking Form II: (a) $\rightarrow$ (b) $\rightarrow$ (c) $\rightarrow$ (d)

When the cutting path of the tool is located in the middle or near the bottom of the grain, only slight damage to the $\mathrm{SiC}$ grains occurs, as shown in Fig. 4 .

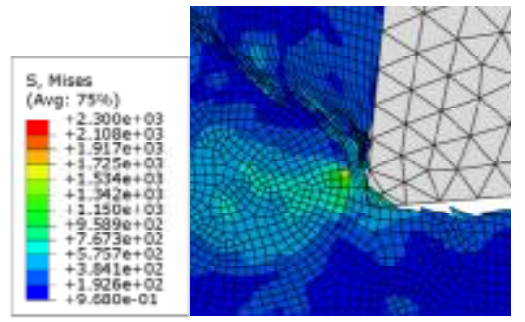

(a)

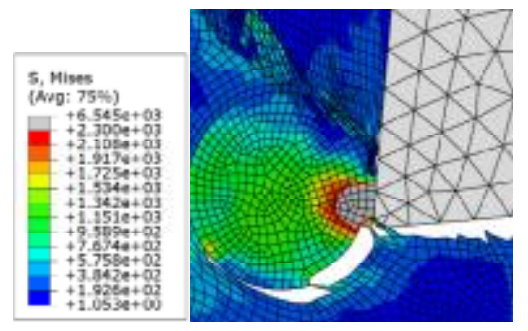

(c)

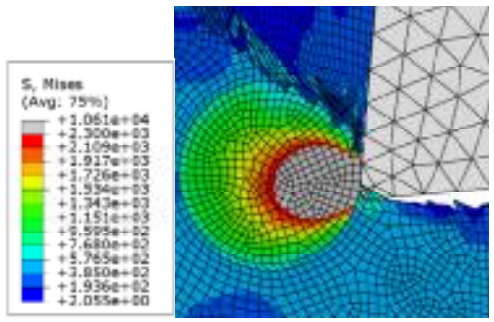

(b)

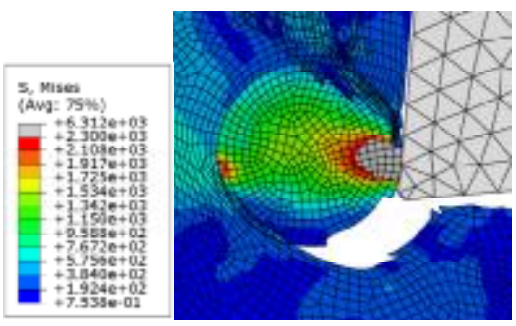

(d)

Fig.4 SiC Particle Breaking Form III: (a) $\rightarrow$ (b) $\rightarrow$ (c) $\rightarrow$ (d)

The part of the cutter that is in contact with the $\mathrm{SiC}$ particles is located in the middle and lower part of the SiC particles, where the stress is greatest. The difference between the fracture pattern I and the fracture pattern II is that the tool has an upward force component on the SiC particles because the contact position is the lower middle part of the particles. The bonding force between the $\mathrm{SiC}$ particles and the aluminum matrix is much smaller than the fracture stress of the $\mathrm{SiC}$, so the $\mathrm{SiC}$ particles will first separate from the aluminum matrix, after which the particles are greatly constrained by the aluminum matrix. Although the tool is still in contact with the particles, due to insufficient constraints, the internal stress of the particles is insufficient to meet the fracture criteria. Therefore, the SiC particles undergo micro-cracks at the bottom only during separation from the substrate. 


\section{Conclusion}

In this paper, a two-dimensional microscopic geometric model of SIC composites is established. The finite element analysis software was used for cutting simulation, Three different fracture patterns of SiC particles were analyzed. It was found that in the early stage of fracture, the stress in the workpiece under the action of the tool was mainly concentrated on the SIC particles, and the $\mathrm{SiC}$ particles fractured in the direction with the highest stress. In the later stage, by optimizing the size of SiC particles, reducing the size of the pits on the processing surface, and reducing the residual stress on the $\mathrm{SiC}$ particles, the dimensional accuracy of the processing can be improved to a certain extent, and the surface roughness of the workpiece can be reduced.

\section{Reference:}

[1]Wang D Z,Shang G Q,Li B. Experimental investigation on the cutting forces of SiCw aluminum composites[J]. Machinery Design \& Manufacture, 2010(3):120-122.

[2] Zhang J Y. Research on Properties of SiCp/Al Composites[D]. Nanjing University of Aeronautics, 2006.

[3] Zhu Y, Kishawy H A. Influence of alumina particles on the mechanics of machining metal matrix composites[J]. International Journal of Machine Tools \& Manufacture, 2005, 45(4):389-398. [4] Vogler M P, Devor R E, Kapoor S G, et al. On the Modeling and Analysis of Machining Performance in Micro-Endmilling, Part I: Surface Generation[J]. Journal of Manufacturing Science \& Engineering, 2004, 126(4):695-705.

[5] Livermore Software Technology Corporation, ANSYS/LS-DYNA Reference Manual, Release 10[DB/OLD], www.lstc.com.

[6] Tan Y, Yang D, Sheng Y. Discrete element method (DEM) modeling of fracture and damage in the machining process of polycrystalline $\mathrm{SiC}[\mathrm{J}]$. Journal of the European Ceramic Society, 2009, 29(6):1029-1037. 